\title{
THÍCH ƯNG VỚI BIẾN ĐỔI KHÍ HậU TRONG MÔ HÌNH QUẢN LÝ ĐÔ TH!̣ TẠI THÀNH PHỐ HỒ CHÍ MINH
}

\author{
Trần Nhật Nguyên', Trịnh Thị Minh Châu', Lê Thị Phụng², \\ Nguyễn Kỳ Phùng ${ }^{3}$
}

Tóm tắt: Đô thị có khả năng thích ưng với biến đổi khi hậu (BĐKH) là đô thị đảm bảo việc cung cấp và vận hành hệ thống hạ tầng đô thị cho người dân trong các tình huống xảy ra thiên tai do tác động của BĐKH. Thành phố Hồ Chí Minh (TP.HCM) đang phải đối diện với nhũng thách thức mói do tác động của BĐKH. Để hạn chế nguy cơ của BĐKH đe dọa đến mục tiêu phát triển, thành phố cần chủ động tăng cuờng khả năng thích ưng. BĐKH tác động đến đa lĩnh vưc, do đó để đánh giá khả năng thích ưng với $B Đ K H$, nhóm nghiên cưu thực hiện khảo sát bằng phiếu hỏi đối với cán bộ công chức quản lý các cấp tại TP.HCM ở 8 lĩnh vực (co sở hạ tầng, dịch vu xã hội, môi truờng, nhà ở - xây dụng - quy hoạch, kinh tế, tu pháp, nghiên cứu, văn phòng - thống kê) dựa trên bộ tiêu chí nhằm đánh giá khả năng thích ứng của các cấp, các ngành trước thách thức của BĐKH. Kết quả đánh giá giúp nhận diện nhũng mặt tồn tại tù̀ đó sẽ có những kiến nghị về điều chỉnh trong công tác quản lý tại TP.HCM nhằm nâng cao khả năng thích úng với BĐKH của TP.HCM.

Từ khóa: Biến đổi khi hậu, khả năng thích ứng, quản lý đô thị, Thành phố Hồ Chí Minh.

\section{Giới thiệu chung}

Nghiên cứu tiếp cận mô hình quản lý đô thị là hệ thống gồm thể chế, chính sách, tổ chức bộ máy, nguồn lực, cơ sở vật chất tác động đến các đối tượng quản lý trong đô thị để thực hiện một cách có hiệu quả các mục tiêu đảm bảo cho đô thị phát triển ổn định bền vững, đảm bảo hài hòa các lợi ích quốc gia, cộng đồng và cá nhân trước mắt và lâu dài [1]. Khả năng thích ứng đề cập đến mức độ điều chỉnh có thể trong hành động, xử lý, cấu trúc của hệ thống đối với những biến đổi dự kiến có thể xảy ra hay thực sự đã và đang xảy ra của khí hậu [2-3]. Theo đó, nghiên cứu xác định khả năng thích ứng với $\mathrm{BĐKH} \mathrm{của} \mathrm{mô}$ hình quản lý đô thị tại TP.HCM là khả năng thích nghi của các công cụ quản lý đô thị (bao gồm thể chế, tổ chức, nguồn lực và cơ sở vật chất) với một loạt những tình huống mới và những biến động bất thường của $\mathrm{B} Đ K H$ đến các đối tượng quản lý.

Tiêu chí là thước đo do các nhà phân tích, nhà quản lý đặt ra trong từng điều kiện và hoàn cảnh cụ thể nhằm đạt được mục tiêu chính sách [4]. Tiêu chí thường được sử dụng để kiểm định hay để đánh giá một đối tượng và được sử dụng làm căn cứ để đánh giá, xếp loại, phân loại một sự vật, hiện tượng. Để đánh giá đô thị có khả năng thích ứng với $\mathrm{BĐKH}$ hay không có thể xem xét đánh giá dựa trên các tiêu chí [5-6]. Ở nước ta, đánh giá hoạt động quản lý nhà nước cũng được nhiều nghiên cứu sử dụng bằng bộ tiêu chí, như bộ tiêu chí thích ứng với BĐKH phục vụ công tác quản lý nhà nước về BĐKH [7]; bộ tiêu chí đánh giá khả năng đáp ứng do di dân trong điều

${ }^{1}$ Viện Nghiên cưu phát triển TPHCM

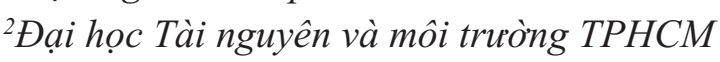

${ }^{3}$ Sở Khoa hoc và Công nghệ TPHCM

Email:tnnguyen.hids@tphcm.gov.vn 
kiện BĐKH [8]; tiêu chí đánh giá mô hình nông nghiệp thông minh thích ứng với biến đổi khí hậu ở Việt Nam, từ đó lựa chọn và đề xuất các mô hình phù hợp để nhân rộng [9];.... Như vậy, sử dụng bộ tiêu chí để đánh giá một đối tượng hoặc một hoạt động đã được nhiều nghiên cứu áp dụng. Trong nghiên cứu này cũng tiếp cận đánh giá khả năng thích ứng với $\mathrm{BĐKH} \mathrm{của} \mathrm{mô}$ hình quản lý đô thị tại TP.HCM bằng bộ tiêu chí.

TP.HCM đang phát triển nhanh, mật độ đô thị ngày càng tăng và đang phải đối mặt với những thách thức của quá trình đô thị hóa. Ngoài ra, Thành phố đang đối diện với những thách thức mới nảy sinh do tác động của $\mathrm{B} Đ K H$ và nước biển dâng do TP.HCM là một trong 10 đô thị lớn bị ảnh hưởng nặng nề bởi BĐKH [10]. Trong bối cảnh $\mathrm{BĐKH}$ toàn cầu, ứng phó với $\mathrm{BĐKH}$ trở thành một thách thức quan trọng đối với quản lý đô thị TP.HCM. Thành phố đang hướng tới một đô thị thích ứng với $\mathrm{BĐKH} \mathrm{và} \mathrm{có} \mathrm{khả} \mathrm{năng}$ chống chịu trong tương lai, do đó cần thiết đánh giá khả năng thích ứng của mô hình quản lý đô thị tại TP.HCM như thế nào để nhận diện những tồn tại hiện nay cần cải thiện.

\section{Phương pháp nghiên cứu}

\subsection{Giới thiệu khu vục nghiên cứu}

TP.HCM nằm trong vùng chuyển tiếp giữa miền Đông Nam bộ và đồng bằng sông Cửu Long. Là đô thị hạt nhân, trung tâm tri thức, trung tâm kinh tế tổng hợp đa chức năng hiện đại ngang tầm với các đô thị trong khu vực Đông Nam Á [11]. TP.HCM đã luôn duy trì tăng trưởng ở mức cao và sự đóng góp của TP.HCM cho cả nước ngày càng lớn. Theo Cục Thống kê của TP.HCM, GRDP của thành phố năm 2019 đóng góp 22,27\% cho GDP của cả nước. Bên cạnh sự phát triển kinh tế, trong những năm qua, thành phố đang phải đối mặt với những thách thức của quá trình đô thị hóa. Quá trình đô thị hoá mang lại nhiều hiệu quả tích cực song cũng làm nảy sinh nhiều vấn đề bất cập trong quy hoạch và quản lý đô thị liên quan đến các khía cạnh về kinh tế - xã hội và môi trường [12]. Là địa phương nằm phía hạ lưu của các con sông lớn như sông Đồng Nai và sông Sài Gòn có địa hình tương đối thấp (gần $63 \%$ diện tích có cao độ tự nhiên $<+1,5 \mathrm{~m})$, TP.HCM đang đối diện với tình trạng ngập lụt không chỉ do mưa mà còn chịu ảnh hưởng bởi thủy triều xâm nhập từ Biển Đông. Bên cạnh đó, những vấn đề khác liên quan đến quản lý đô thị như ùn tắc giao thông, ô nhiễm môi trường ngày càng nghiêm trọng đã ảnh hưởng không nhỏ đến khả năng đạt được các mục tiêu phát triển của Thành phố trong tương lai.

Để ứng phó tốt hơn trong điều kiện BĐKH đòi hỏi phải nâng cao năng lực quản lý đô thị, tăng cường sự phối hợp, chia sẻ thông tin giữa các bên liên quan, có hệ thống thể chế chính sách ứng phó phù hợp và đầu tư vào cơ sở hạ tầng đô thị [5]. Đến nay, do chưa có định nghĩa mang tính pháp lý về "quản lý đô thị” nên cách tiếp cận về mô hình quản lý đô thị trong nghiên cứu dựa trên các khái niệm được các nhà nghiên cứu đưa ra. Theo đó, mô hình quản lý đô thị được xác định là hệ thống gồm thể chế, chính sách, tổ chức bộ máy, nguồn lực, cơ sở vật chất tác động đến các đối tượng quản lý trong đô thị [1,13]. Dựa trên tổng hợp các văn bản hiện hành, các nghiên cứu liên quan và thực tế quản lý tại TP.HCM, đối tượng trong mô hình quản lý đô thị được đề cập trong nghiên cứu này gồm 8 lĩnh vực: cơ sở hạ tầng, dịch vụ xã hội, môi trường, nhà ở - xây dựng - quy hoạch, kinh tế, tư pháp, nghiên cứu, văn phòng - thống kê. Về cơ bản, mô hình bộ máy quản lý đô thị của một đô thị có vị trí, vai trò đặc biệt như TP.HCM không khác gì mô hình quản lý của các tỉnh, thành khác [14].

Với vai trò quan trọng trong khu vực và cả nước, để đảm bảo các mục tiêu phát triển kinh tế xã hội của TP.HCM, việc đánh giá khả năng thích ứng với $\mathrm{BĐKH} \mathrm{của} \mathrm{mô} \mathrm{hình} \mathrm{quản} \mathrm{lý} \mathrm{để} \mathrm{xác}$ định những tồn tại, từ đó có giải pháp nâng cao 
khả năng thích ứng của thành phố là cần thiết, nhằm đạt được những thành quả về tăng trưởng kinh tế theo hướng bền vững.

\subsection{Phương pháp nghiên cứu}
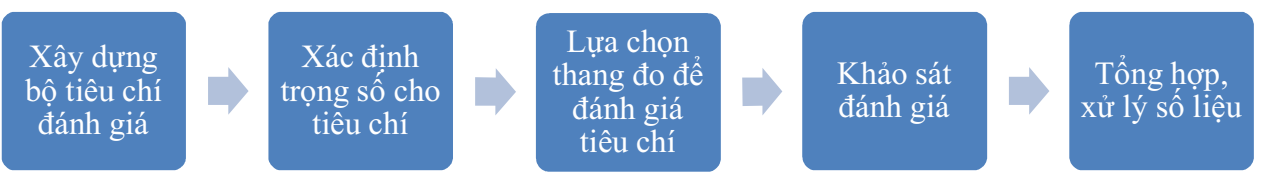

Để đánh giá thực trạng khả năng thích ứng với $\mathrm{BĐKH}$ của mô hình quản lý đô thị tại TP.HCM, nhóm nghiên cứu thực hiện theo các bước sau [8]:
2.2.1 Phương pháp xây dụng bộ tiêu chí đánh giá

Để có cơ sở đề xuất bộ tiêu chí đánh giá, nhóm nghiên cứu dựa trên học tập kinh nghiệm của các nghiên cứu trong và ngoài nước [5-7, $8,15]$, điều chỉnh dựa trên cơ sở pháp lý của Việt Nam và lấy ý kiến chuyên gia để đưa ra các tiêu chí đánh giá phù hợp với định hướng phát triển của TP.HCM trong bối cảnh BĐKH. Đồng thời, chú trọng các đặc điểm sau đây: (1) Có thể lượng hóa kết quả đánh giá; (2) Có thể thu thập được số liệu/dữ liệu phục vụ đánh giá; (3) Phù hợp với mục đích nghiên cứu; (3) Rõ ràng, dễ hiểu, không trùng lắp.

Theo đó, nhóm nghiên cứu lựa chọn 6 tiêu chí chính, bao gồm: (1) Nhận thức của cán bộ công chức, viên chức về BĐKH; (2) Thể chế, chính sách liên quan đến BĐKH; (3) Công tác phối hợp với các bên liên quan; (4) Cơ cấu tổ chức, nguồn nhân lực liên quan đến BĐKH; (5) Cơ chế tài chính về BĐKH; (6) Cơ sở hạ tầng trong điều kiện BĐKH. Mỗi tiêu chí chính sẽ được đánh giá bằng các tiêu chí phụ khác nhau để xem xét nhiều khía cạnh liên quan và mỗi tiêu chí đánh giá sẽ được lượng hóa bằng các giá trị tính toán cụ thể dựa trên dựa trên kết quả khảo sát thực tế đối với đối tượng đánh giá. Trong 6 tiêu chí chính đề cập ở trên bao gồm 23 tiêu chí phụ (bảng 3).

2.2.2 Xác định múc độ quan trọng của tiêu chí thông qua trọng số

a) Lựa chọn phương pháp

Lựa chọn phương pháp phân tích thứ bậc AHP (Analytic Hierarchy Process) [16] để xác định trọng số cho tiêu chí. Bởi vì, AHP là một phương pháp phân tích định lượng thường sử dụng để so sánh lựa chọn phương án. AHP giúp người đánh giá thu được các kết quả đánh giá chủ quan và khách quan, kiểm tra mức độ hợp lý của các đánh giá và vì vậy giảm được các sai số trong quá trình ra quyết định. Phương pháp này bắt đầu từ việc xây dựng sơ đồ thứ bậc, bao gồm một số bước so sánh từng cặp nhân tố (tiêu chí) trong từng bậc, lần lượt đi từ các tiêu chí chính đến các tiêu chí phụ. Kết quả so sánh trong từng bậc chính là trọng số (mức độ quan trọng).

Các bước tiến hành AHP như sau:

Bước 1: Phân tích vấn đề và xác định lời giải yêu cầu.

Bước 2: Xác định các yếu tố sử dụng và xây dựng cây phân cấp yếu tố.

Bước 3: Điều tra thu thập ý kiến chuyên gia về mức độ ưu tiên.

Bước 4: Thiết lập các ma trận so sánh cặp.

Bước 5: Tính toán trọng số cho từng mức, từng nhóm yếu tố.

Bước 6: Tính tỷ số nhất quán $(\mathrm{CR})$. Tỷ số nhất quán phải nhỏ hơn hay bằng $10 \%$, nếu lớn hơn, cần thực hiện lại các bước 3, 4, 5 .

Bước 7: Thực hiện bước 3, 4, 5, 6 cho tất cả các mức và các nhóm yếu tố trong cây phân cấp.

Bước 8: Tính toán trọng số tổng hợp và nhận xét.

Tỉ số về tính nhất quán $(\mathrm{CR}$ - Consistency Ratio) được xác định theo công thức :

$$
C R=\frac{C I}{R I} \text { với } \quad C I=\frac{\lambda_{\max }-n}{n-1}
$$

Trong đó CI (Consistency Index) là chỉ số về 
tính nhất quán; RI (Random Index) là chỉ số ngẫu nhiên (được xác định sẵn theo kích thước ma trận); $\lambda$ max là giá trị trung bình của các vector nhất quán; $n$ là kích thước của ma trận. $\lambda \max$ được xác định đựa trên vector nhất quán. Vector nhất quán = vector tổng có trọng số/vector trọng số.

Chúng ta có thể sử dụng phần mềm Expert Choice 11.0 hỗ trợ trong việc tính toán theo phương pháp quá trình phân tích thứ bậc AHP.

b) Lựa chọn chuyên gia để đánh giá trọng số của tiêu chí

Số lượng chuyên gia tối thiểu được đề nghị lấy ý kiến cho phương pháp AHP từ 5 đến 7 người với cơ cấu thích hợp. Nhóm nghiên cứu đã thực hiện lấy ý kiến với 37 chuyên gia ở các lĩnh vực cơ sở hạ tầng, quy hoạch xây dựng, môi trường và $\mathrm{BĐKH}$, kinh tế và về nhà ở (bao gồm đại diện các Sở có thành viên trong Ban chỉ đạo thực hiện Kế hoạch hành động ứng phó với BĐKH của TP.HCM (từ cấp Phó phòng trở lên), đại diện cấp Quận/Huyện, đại diện các nhà khoa học) bằng bảng hỏi $\mathrm{AHP}$ để xác định các trọng số cho các tiêu chí chính và tiêu chí phụ. Các ý kiến của các chuyên gia được xem như có vai trò quan trọng như nhau (có cùng "trọng số"). Phương pháp thu thập ý kiến: sử dụng phương pháp hỗn hợp, tiếp xúc trực tiếp với chuyên gia để giải thích mục đích và nội dung khi cần.

\subsection{Lụa chọn thang đo đánh giá tiêu chí}

Sau khi xác định các trọng số cho tiêu chí chính và các tiêu chí phụ, đối với mỗi tiêu chí phụ xây dựng 5 mức độ xem xét theo kiểu tính điểm Likert từ thấp đến cao, từ mức 1 đến mức 5. Thang đo chia thành 5 khoảng vì những lý do chính như sau: (1) vừa đủ để đánh giá; (2) có điểm trung bình trong đánh giá; (3) phù hợp với thang đo dùng phổ biến hiện nay; (4) phù hợp ý kiến chuyên gia.

- Điểm của từng tiêu chí là được tính theo thang điểm $1-5$, điểm số trung bình là 3 . Mỗi mức độ được cụ thể hóa và diễn giải trong bảng hỏi định lượng cho từng tiêu chí để đối tượng khảo sát có thể lựa chọn mức độ đánh giá phù hợp.

- Điểm đánh giá chung theo cách tính trung bình có trọng số cũng có cùng thang đo là 5 , giá trị trung bình là 3 . Giá trị trung bình của các điểm đánh giá chung của toàn bộ cán bộ, công chức, viên chức là điểm đánh giá trung bình và được phân theo 2 hình thức để phân tích: (1) theo cấp chính quyền: 3 cấp (cấp Sở/ngành, cấp Quận/Huyện và cấp Phường/xã); (2) và phân theo lĩnh vực quản lý. Quy ước phân loại:

- Điểm từ 1 đến 2 : Khả năng thích ứng ở mức độ hạn chế.

- Điểm từ 2 đến 3: Khả năng thích ứng ở mức độ dưới trung bình.

- Điểm từ $\geq 3$ đến 4 : Khả năng thích ứng ở mức độ tốt.

- Điểm từ $\geq 4$ đến 5 : Khả năng thích ứng ở mức độ rất tốt.

$\begin{array}{ccccc}\text { Rất hạn chế } & \text { Hạn chế } & \text { Trung bình } & \text { Tốt } & \text { Rất tốt } \\ \text { Thang đo } & 1 & 3 & 4 & 5 \\ & & & \end{array}$

\subsection{Khảo sát đánh giá}

Đối tượng khảo sát: cán bộ, công chức, viên chức khối Nhà nước.

Quy mô mẫu được xác định theo công thức [17]:

$$
n=\frac{N}{1+\mathrm{N} * e^{2}}
$$

Trong đó $\mathrm{n}$ là cỡ mẫu; $\mathrm{N}$ là số lượng tổng thể ( $\mathrm{N}=68.878$ cán bộ, công chức khối Thành phố, Quận/Huyện và Phường/xã năm 2018 [14]); e là

sai số tiêu chuẩn (độ chính xác là $96 \%$, ứng với e là $4 \%$ ).

Theo đó, tổng số mẫu khảo sát là 693 , trong đó: có 166 phiếu tại 20 Sở/ngành (tỷ lệ 24,0\%); 247 phiếu tại 24 quận/huyện (tỷ lệ 35,6\%) và 280 phiếu tại 72 phường/xã (tỷ lệ 40,4\%).

\subsection{Tổng hợp đánh giá số liệu sau khảo sát}

Khả năng thích ứng của chính quyền Thành phố trong điều kiện BĐKH được xác định thông 
qua kết quả khảo sát với bảng hỏi định sẵn dựa trên bộ tiêu chí đã được xây dựng. Mỗi tiêu chí phụ được đánh giá với 5 mức như đã trình bày ở mục trên. Điểm đánh giá theo từng tiêu chí phụ là điểm trung bình cộng số học của các đánh giá tương ứng tiêu chí phụ đó. Điểm đánh giá của các tiêu chí chính là điểm trung bình có trọng số (trọng số tương đối trong tiêu chí chính tương ứng). Ngoài các phương pháp như đã đề cập ở trên, nhóm nghiên cứu còn sử dụng phần mềm SPSS (Statistical Package for the Social Sci- ences) để phân tích xử lý số liệu điều tra.

\section{Kết quả nghiên cứu}

3.1. Kết quả trọng số cho tiêu chí đánh giá khả năng ứng phó BĐKH của mô hình quản lý đô thị TP.HCM

Các tiêu chí sẽ được đánh giá mức độ quan trọng và cho điểm theo thang điểm của phương pháp AHP từ 1 đến 9 khi các cặp tiêu chí được so sánh với nhau [16]. Điểm số đánh giá cho các cặp tiêu chí sẽ được thiết lập ở dạng ma trận so sánh.

Bảng 1. Thang điểm đánh giá mức độ quan trọng của các tiêu chí theo phưong pháp AHP [15]

\begin{tabular}{cl}
\hline Điểm số đánh giá & \multicolumn{1}{c}{ Mức độ quan trọng của cặp tiêu chí $\mathrm{i}$ và $\mathrm{j}$} \\
\hline 1 & Tiêu chí $\mathrm{i}$ có mức độ quan trọng bằng vớ tiêu chí $\mathrm{j}$ \\
3 & Tiêu chí $\mathrm{i}$ có mức độ quan trợg hơi nhiều hơn so với tiêu chí $\mathrm{j}$ \\
5 & Tiêu chí $\mathrm{i}$ có mức độ quan trọng nhiều hơn so với tiêu chí $\mathrm{j}$ \\
7 & Tiêu chí $\mathrm{i}$ có mức độ quan trọng rất nhiều so với tiêu chí $\mathrm{j}$ \\
9 & Tiêu chí $\mathrm{i}$ cực kỳ quan trọng với tiêu chí $\mathrm{j}$ \\
\hline
\end{tabular}

Trong đó, các giá trị 2,4,6,8 là các giá trị trung gian giữa các khoảng đánh giá trên.

Ma trận này thể hiện đánh giá của chuyên gia về so sánh cặp nên đòi hỏi phải có độ nhất quán về các chỉ số đánh giá. Do đó, kiểm tra tính không nhất quán cần được thực hiện để xác định mức độ nhất quán trong đánh giá của chuyên gia. Tỉ số về tính nhất quán CR cho phép của các so sánh phải $\leq 0,1(10 \%)$. Nếu tỉ số này $>10 \%$, trọng số đánh giá cho các tiêu chí cần được đánh giá lại.

Kết quả lấy ý kiến chuyên gia bằng bảng hỏi AHP để xác định trọng số cho tiêu chí được xử lý bởi phần mềm chuyên dùng Expert Choice 11.0. Các kết quả nhận được cho thấy có 21/37 phiếu ý kiến đạt tỷ số nhất quán $\mathrm{CR} \leq 0,1$. Do đó, kết quả tính toán trọng số dựa trên 21 phiếu có tỷ số nhất quán đủ chuẩn để phân tích. Kết quả tổng hợp của trọng số như sau:

Bảng 2. Trọng số cho các tiêu chí chính

\begin{tabular}{llr}
\hline & \multicolumn{1}{c}{ Tiêu chí chính } & \multicolumn{1}{c}{ Trọng số } \\
\hline 1 & Nhận thức về BĐKH & 0,12 \\
2 & Thề chế chính sách & 0,16 \\
3 & Công tác phối hợp & 0,10 \\
4 & Nguồn nhân lực & 0,13 \\
5 & Tài chính & 0,26 \\
6 & Quy hoạch cơ sở hạ tầng & 0,23 \\
\hline
\end{tabular}

Kết quả cho thấy trong 6 tiêu chí chính, tiêu tầng và tiêu chí quan trọng thứ 3 là Thể chế chí Tài chính được xem là quan trọng nhất, tiêu chính sách. Thấp nhất là tiêu chí về Công tác chí quan trọng tiếp theo là Quy hoạch cơ sở hạ phối hợp.

Bảng 3. Trọng số các tiêu chi phu

\begin{tabular}{|c|c|c|c|c|}
\hline STT & Tiêu chí & \multicolumn{2}{|c|}{ Trọng số } & Ghi chú \\
\hline 1 & Tiêu chí về nhận thức & Tương đối & Tuyệt đối & \\
\hline 1.1 & Hiểu biết cơ bản về BĐKH & 0,14 & 0,02 & Mối quan tâm của lãnh đạo về BĐKH \\
\hline 1.2 & Cơ sở dữ liệu sẵn có & 0,23 & 0,03 & được xem là quan trọng nhất. Lần lượt \\
\hline 1.3 & Mối quan tầm của lãnh đạo & 0,42 & 0,05 & theo thứ tự giảm dần là Sự hiểu biết về \\
\hline 1.4 & Mức độ cập nhật kiến thức & 0,21 & 0,03 & $\begin{array}{l}\text { cơ sở dữ liệu sẵn có, mức độ cập nhất } \\
\text { kiến thức về } B Đ K H \text { và những hiều biêt } \\
\text { cơ bản về } \mathrm{BĐKH.}\end{array}$ \\
\hline
\end{tabular}




\begin{tabular}{|c|c|c|c|c|}
\hline 2 & $\begin{array}{l}\text { Tiêu chí về Thể chế chính } \\
\text { sách }\end{array}$ & & & \multirow{6}{*}{$\begin{array}{l}\text { Tính khả thi của chính sách được xem } \\
\text { là quan trọng nhất. Lần lượt theo thứ tự } \\
\text { giảm dần là Mục tiêu của chính sách, } \\
\text { tính hiệu quả của chính sách, sự lồng } \\
\text { ghép BĐKH vào ngành quản lý và cuối } \\
\text { cùng là Tính bao quát, đầy đủ của } \\
\text { chính sách. }\end{array}$} \\
\hline 2.1 & $\begin{array}{l}\text { Tính bao quát, đầy đủ của } \\
\text { chính sách }\end{array}$ & 0,13 & 0,02 & \\
\hline 2.2 & Tính khả thi của chính sách & 0,27 & 0,04 & \\
\hline 2.3 & Tính hiệu quả của chính sách & 0,20 & 0,03 & \\
\hline 2.4 & $\begin{array}{l}\text { Sự lồng ghép BĐKH vào } \\
\text { ngành quản lý }\end{array}$ & 0,15 & 0,02 & \\
\hline 2.5 & $\begin{array}{l}\text { Mục tiêu cụ thể, có thể đo } \\
\text { lường được }\end{array}$ & 0,25 & 0,04 & \\
\hline 3 & $\begin{array}{l}\text { Tiêu chí về sư phối hợp giữa } \\
\text { các bên liên quan }\end{array}$ & & & \multirow{4}{*}{$\begin{array}{l}\text { Tiêu chí về Sự chia sẻ dữ liệu giữa các } \\
\text { bên liên quan được xem là quan trọng } \\
\text { nhất. Tiếp đến là tiêu chí về Cơ chề } \\
\text { làm việc và cuối cùng là sự tham gia } \\
\text { phối hợp giữa các bên và cuối cùng là }\end{array}$} \\
\hline 3.1 & $\begin{array}{l}\text { Sự chia sẻ dữ liệu giữa các } \\
\text { bên liên quan }\end{array}$ & 0,43 & 0,04 & \\
\hline 3.2 & $\begin{array}{l}\text { Sự tham gia phối hợp giữa } \\
\text { các bên }\end{array}$ & 0,28 & 0,03 & \\
\hline 3.3 & Cơ chế làm việc & 0,29 & 0,03 & \\
\hline 4 & Tiêu chí về nguồn nhân lục & & & \multirow{4}{*}{$\begin{array}{l}\text { Tiêu chí Trình độ chuyên môn được } \\
\text { xem là quan trọng nhất, tiếp đến là co } \\
\text { cấu tổ chức, cuối cùng mới đến số } \\
\text { lượng nhân sự }\end{array}$} \\
\hline 4.1 & Số lượng nhân sự tham gia & 0,24 & 0,03 & \\
\hline 4.2 & Trình độ chuyên môn & 0,41 & 0,05 & \\
\hline 4.3 & Cơ cấu tổ chức & 0,36 & 0,05 & \\
\hline 5 & Tiêu chí về nguồn kinh phí & & & \multirow{5}{*}{$\begin{array}{l}\text { Tiêu chí Tính liên tục của kinh phí } \\
\text { được xem là quan trọng nhất, tiếp đến } \\
\text { là các nguồn tài trợ cho } \mathrm{BĐKH}\end{array}$} \\
\hline 5.1 & Nguồn kinh phí & 0,19 & 0,05 & \\
\hline 5.2 & Thủ tục cấp kinh phí & 0,21 & 0,05 & \\
\hline 5.3 & Tính liên tục của kinh phí & 0,34 & 0,09 & \\
\hline 5.4 & Nguồn tài trợ khác & 0,26 & 0,07 & \\
\hline 6 & $\begin{array}{l}\text { Tiêu chí quy hoạch co' sở hạ } \\
\text { tầng }\end{array}$ & & & \multirow{5}{*}{$\begin{array}{l}\text { Tiêu chí về quy hoạch có được tính } \\
\text { đến yếu tố biến đổi khí hậu được xem } \\
\text { là quan trọng nhất }\end{array}$} \\
\hline 6.1 & $\begin{array}{l}\text { Khả năng đáp ứng của cơ sở } \\
\text { hạ tầng thời điểm hiện nay }\end{array}$ & 0,10 & 0,02 & \\
\hline 6.2 & $\begin{array}{l}\text { Khả năng đáp ứng của cơ sở } \\
\text { hạ tầng trong điều kiện } \\
\text { BĐKH }\end{array}$ & 0,24 & 0,06 & \\
\hline 6.3 & $\begin{array}{l}\text { Lộ trình xây dựng cơ sở hạ } \\
\text { tầng theo quy hoạch }\end{array}$ & 0,26 & 0,06 & \\
\hline 6.4 & $\begin{array}{l}\text { Quy hoạch có tính yếu tố } \\
\text { BĐKH }\end{array}$ & 0,40 & 0,09 & \\
\hline
\end{tabular}

Trong đó: Trọng số tương đối thể hiện mức độ quan trọng giữa các tiêu chí phụ trong tiêu chí chính; Trọng số tuyệt đối bằng trọng số tương

đối của tiêu chí phụ nhân với trọng số của tiêu chí chính tương ứng. Trọng số tuyệt đối được dùng khi so sánh giữa các tiêu chí phụ cùng cấp.

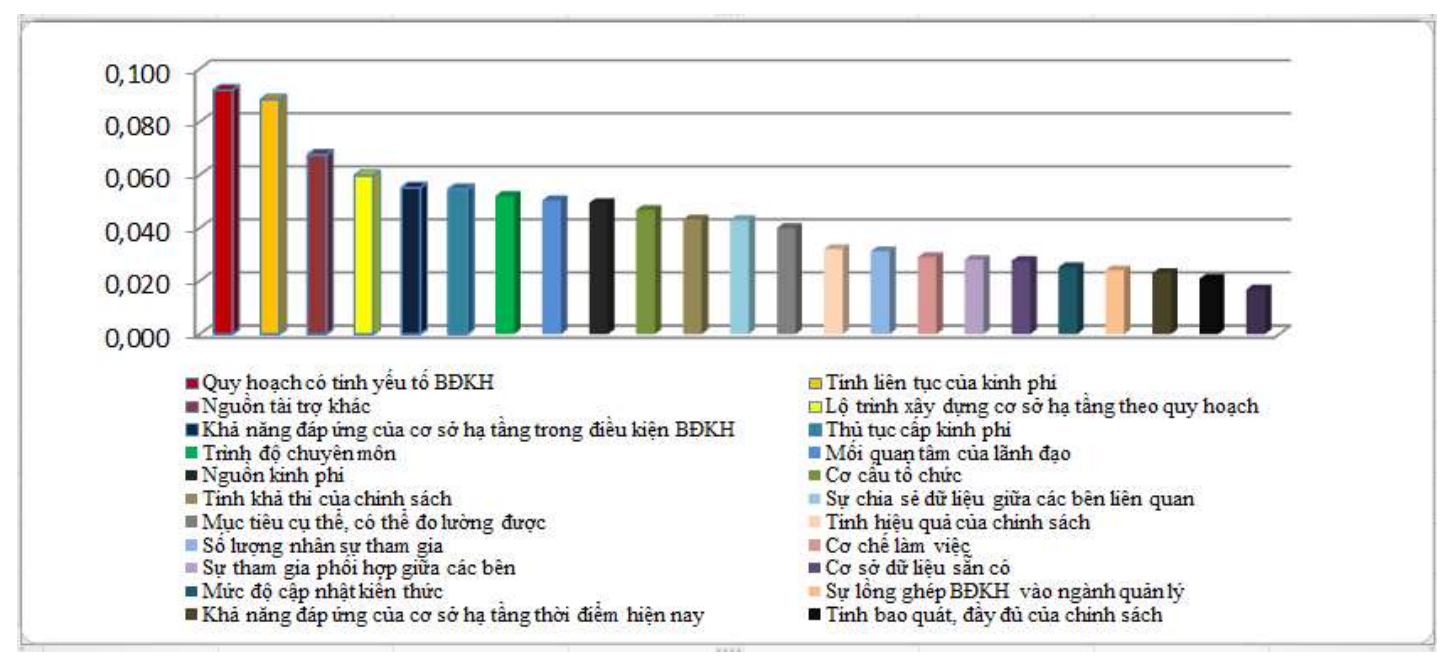

Hình 1. Trọng số các tiêu chí phu được sắp xếp tù̀ cao đến thấp 
Hình 1 thể hiện sự sắp xếp giảm dần thông qua giá trị trọng số của các tiêu chí. Dựa vào trọng số tuyệt đối của các tiêu chí, chúng ta có thể phân loại các tiêu chí phụ vào các nhóm có mức độ quan trọng khác nhau. Theo đó, chúng tôi lựa chọn mức độ ưu tiên theo thứ tự mức độ ưu tiên giảm dần từ ưu tiên 1 đến ưu tiên 10 trong nhóm mức độ quan trọng nhất dựa trên việc sắp xếp giá trị từ cao đến thấp của các tiêu chí. Sự sắp xếp này được dùng làm cơ sở cho việc lựa chọn ưu tiên các giải pháp và xây dựng các biện pháp nhằm nâng cao khả năng thích ứng với BĐKH tại TP.HCM.

\section{Bảng 4. Sắp xếp các tiêu chuẩn phụ vào các nhóm ưu tiên}

\begin{tabular}{|c|c|c|}
\hline STT & Tiêu chí & \\
\hline 1 & Quy hoạch có tính yếu tố BĐKH & U’u tiên 1 \\
\hline 2 & Tính liên tục của kinh phí & U’u tiên 2 \\
\hline 3 & Nguồn tài trợ bên ngoài cho vấn đề $\mathrm{BĐKH}$ & U’u tiên 3 \\
\hline 4 & Lộ trình xây dựng cơ sở hạ tầng theo quy hoạch & U’u tiên 4 \\
\hline 5 & $\begin{array}{l}\text { Khả năng đáp ứng của cơ sở hạ tầng trong điều } \\
\text { kiện BĐKH }\end{array}$ & Uu tiên 5 \\
\hline 6 & Thủ tục cấp kinh phí & Uu tiên 6 \\
\hline 7 & $\begin{array}{l}\text { Trình độ chuyên môn của cán bộ quản lý về } \\
\text { BĐKH }\end{array}$ & U’u tiên 7 \\
\hline 8 & Mối quan tâm của lãnh đạo về BĐKH & Uu tiên 8 \\
\hline 9 & Nguồn kinh phí cung cấp cho vấn đề BĐKH & Uu tiên 9 \\
\hline 10 & Cơ cấu tồ chức quản lý về BĐKH & Uu tiên 10 \\
\hline
\end{tabular}

3.2. Đánh giá chung về khả năng thích ứng trọng số) của 6 nhóm tiêu chí chính và 23 tiêu với BĐKH của mô hình quản lý đô thị tại chí phụ thông qua kết quả khảo sát. Điểm đánh TP.HCM

Khả năng thích ứng với $\mathrm{BĐKH} \mathrm{của} \mathrm{mô} \mathrm{hình}$ quản lý đô thị tại TP.HCM được xác định là kết quả tổng hợp từ các giá trị trung bình (có tính giá chung có trọng số cũng có giá trị từ 1 đến 5 (tương ứng khả năng thích ứng từ rất hạn chế (giá trị 1) đến rất tốt (giá trị 5), giá trị trung bình là 3 .

Bảng 5. Khả năng thích úng với BĐKH (phân theo cấp quản lý)

\begin{tabular}{|c|c|c|c|c|c|c|c|}
\hline Cấp & $\begin{array}{l}\text { Nhận thức } \\
\text { của cán } \\
\text { bộ, công } \\
\text { chức, viên } \\
\text { chức về } \\
\text { BĐKH }\end{array}$ & $\begin{array}{c}\text { Thể chế, } \\
\text { chính } \\
\text { sách } \\
\text { liên } \\
\text { quan } \\
\text { đến } \\
\text { BĐKH }\end{array}$ & $\begin{array}{l}\text { Công } \\
\text { tác phối } \\
\text { hợp với } \\
\text { các đơn } \\
\text { vị khác }\end{array}$ & $\begin{array}{l}\text { Cơ cấu tổ } \\
\text { chức, } \\
\text { nguồn } \\
\text { nhân lực } \\
\text { quản lý } \\
\text { liên quan } \\
\text { BĐKH }\end{array}$ & $\begin{array}{l}\text { Cơ chế } \\
\text { tài chính } \\
\text { về thích } \\
\text { ứng với } \\
\text { BĐKH }\end{array}$ & $\begin{array}{l}\text { Cơ sở vật } \\
\text { chất cho } \\
\text { công tác } \\
\text { thích ứng } \\
\text { với } \\
\text { BĐKH }\end{array}$ & $\begin{array}{l}\text { Điểm } \\
\text { trung } \\
\text { bình } \\
\text { (có } \\
\text { tính } \\
\text { trọng } \\
\text { số) }\end{array}$ \\
\hline Trọng số & 0,12 & 0,16 & 0,1 & 0,13 & 0,26 & 0,23 & \\
\hline Sở/ngành & 3,07 & 2,42 & 2,67 & 2,32 & 2,18 & 2,21 & 2,40 \\
\hline Quận/Huyện & 2,91 & 2,34 & 2,50 & 1,72 & 1,85 & 2,06 & 2,15 \\
\hline Phường/Xã & 2,85 & 2,33 & 2,48 & 1,68 & 1,85 & 2,10 & 2,15 \\
\hline Điểm TB & 2,92 & 2,35 & 2,53 & 1,85 & 1,93 & 2,11 & 2,21 \\
\hline
\end{tabular}

Kết quả khảo sát cho thấy, giá trị đánh giá chung có tính trọng số của tiêu chí thể hiện khả năng ứng phó của mô hình quản lý đô thị tại TP.HCM là 2,21, ở mức dưới trung bình. Các giá trị của từng tiêu chí chính và tiêu chí phụ phần lớn dưới trung bình. Ngoại trừ tiêu chí về nhận thức của cán bộ, công chức, viên chức về BĐKH của nhóm Sở ngành $(3,07)$ và nhóm ngành Môi trường $(3,07)$ và quản lý về cơ sở hạ tầng $(2,99)$. Xét trong từng tiêu chí được đánh giá cụ thể như sau:

1. Nhận thức của cán bộ công chức, viên chức về BĐKH: điểm đánh giá chung của tiêu chí này chỉ ở mức gần trung bình $(2,92)$. Ở mức điểm 
này cho thấy, nhận thức về $\mathrm{BĐKH} \mathrm{của} \mathrm{cán} \mathrm{bộ,}$ công chức, viên chức tại TP.HCM chưa cao, chỉ có những hiểu biết cơ bản về $\mathrm{BĐKH}$, trong khi nguồn thông tin dữ liệu về BĐKH chưa được tiếp cận dễ dàng, đồng thời mức độ cập nhật kiến thức liên quan đến $\mathrm{BĐKH}$ cũng không thường xuyên. Xét từng tiêu chí phụ có một số điểm đáng lưu ý:

- Phần lớn các đối tượng đều có những hiểu biết cơ bản về $\mathrm{BĐKH} \mathrm{(có} \mathrm{giá} \mathrm{trị} \mathrm{trên} 3$, trừ nhóm quản lý về dịch vụ xã hội và nhóm Tư pháp), điểm cao nhất ở nhóm ngành Môi trường, Nghiên cứu và Cơ sở hạ tầng; nếu phân theo cấp quản lý thì Sở ngành có điểm đánh giá cao hơn Quận/Huyện và Phường xã. Điều này là do các nhóm ngành trên có liên quan trực tiếp đến vấn đề $\mathrm{BĐKH}$ và là các đối tượng có đào tạo, bồi dưỡng, tập huấn liên quan.

- Đánh giá về nguồn dữ liệu sẵn có liên quan đến $\mathrm{BĐKH}$, phần lớn đều đánh giá ở mức không có thông tin, dữ liệu sẵn có, nếu có chỉ tìm được trên internet những thông tin cơ bản về BĐKH, khó tiếp cận về mặt dữ liệu chuyên môn (dưới mức 3). Nhóm ngành Nghiên cứu và Tư pháp đánh giá thấp nhất.

- Đánh giá về mối quan tâm của lãnh đạo, lãnh đạo chính trị được xem là điều kiện tiên quyết để hoạch định chính sách khí hậu địa phương thành công. Qua kết quả khảo sát cho thấy, ngành Môi trường và cơ sở hạ tầng có mức đánh giá cao nhất và trên mức trung bình $(3,1)$, có thể diễn giải ở mức này là lãnh đạo đã quan tâm và chỉ đạo thực hiện các nhiệm vụ liên quan đến BĐKH khi có sự chỉ đạo hay văn bản của cấp trên. Nhưng các ngành khác đều đánh giá ở mức độ lãnh đạo có đề cập đến nhưng chưa chủ động chỉ đạo các vấn đề liên quan đến $\mathrm{BĐKH}$ (đánh giá dưới trung bình).

- Về mức độ cập nhật kiến thức về BĐKH, nhóm ngành Môi trường, Nghiên cứu và Cơ sở hạ tầng có điểm đánh giá cao hơn các ngành khác và ở mức trung bình. Kiến thức được cập nhập chủ yếu thông qua các buổi hội thảo, tọa đàm liên quan.

2. Thể chế, chính sách liên quan đến BĐKH: điểm đánh giá chung của tiêu chí này ở mức dưới trung bình $(2,35)$. Thể hiện thể chế, chính sách còn hạn chế về tính bao quát, đầy đủ; tính khả thi; tính hiệu quả; mức độ lồng ghép $\mathrm{BĐKH} \mathrm{vào}$ quản lý ngành và các mục tiêu của thể chế, chính sách liên quan đến BĐKH chưa rõ ràng cụ thể và có thể đo lường được. Kết quả này cho thấy, thể chế chính sách liên quan đến BĐKH chưa bao quát đầy đủ các đối tượng và lĩnh vực, tính khả thi chưa cao do khó triển khai thực hiện hoặc chỉ thực hiện ở mức độ tương đối vì chưa được cụ thể rõ ràng, dẫn đến hiệu quả không cao, tác động của chính sách rất hạn chế. Nhìn chung, đánh giá của các nhóm ngành khá đồng nhất, không có sự khác biệt lớn về điểm số giữa các ngành. Chỉ với tiêu chí "lồng ghép các thách thức, kịch bản BĐKH vào quản lý ngành" một số ngành đánh giá dưới 2 , trong đó lĩnh vực Tư pháp và Nghiên cứu đánh giá thấp nhất, thể hiện các nội dung BĐKH được lồng ghép không được rõ ràng trong quản lý ngành. Nếu xét về cấp quản lý, hầu hết các thể chế, chính sách liên quan đến BĐKH hiện nay đều được tập trung xây dựng ở cấp thành phố và các đơn vị Sở/ngành là những đơn vị chính được phân công phối hợp, chủ trì thực hiện các chương trình, hành động, dự án... liên quan đến $\mathrm{BĐKH}$, do đó, khả năng tiếp cận cũng như sự hiểu biết của các cán bộ, công chức, viên chức tại các đơn vị Sở/ngành về các thể chế, chính sách liên quan đến BĐKH cũng như mức độ lồng ghép $\mathrm{BĐKH} \mathrm{vào} \mathrm{công} \mathrm{tác} \mathrm{quản} \mathrm{lý,}$ nguồn lực, phương tiện tham gia thực hiện các chương trình, dự án BĐKH cao hơn so với Quận/Huyện và Phường/Xã.

3. Công tác phối hợp giữa các đơn vị trong các vấn đề liên quan đến $\mathrm{BĐKH:} \mathrm{điểm} \mathrm{đánh} \mathrm{giá}$ chung cho tiêu chí này ở mức dưới trung bình 
$(2,53)$. Tương ứng với mức điểm này thể hiện: phương thức chia sẻ cơ sở dữ liệu và thông tin liên quan đến $\mathrm{BĐKH} \mathrm{trong} \mathrm{công} \mathrm{tác} \mathrm{phối} \mathrm{hợp} \mathrm{là}$ bằng văn bản khi có yêu cầu cung cấp thông tin, chưa có cơ chế trao đổi thông tin, dữ liệu dùng chung về BĐKH; Đơn vị chủ yếu phối hợp triển khai một hoặc một vài nhiệm vụ ứng phó với BĐKH của Thành phố; Riêng với tiêu chí "đánh giá về cơ chế phối giữa các bên" hầu hết các nhóm ngành đều đánh giá dưới mức thấp (dưới hoặc bằng 2), điều này thể hiện cơ chế làm việc và phối hợp giữa các bên liên quan chưa thực sự gắn kết, chủ động, hầu như chỉ làm việc thông qua công văn, văn bản.

4. Cơ cấu tổ chức, nguồn nhân lực quản lý liên quan đến $\mathrm{BĐKH:} \mathrm{điểm} \mathrm{đánh} \mathrm{giá} \mathrm{chung} \mathrm{cho}$ tiêu chí này dưới mức hạn chế (chỉ có 1,85 ), trong đó đối tượng Quận/Huyện và Phường/Xã chỉ có 1,72 và 1,68 . Ngoài ngành Môi trường có chỉ số đánh giá trên 2 , các ngành khác đều cho giá trị ở mức dưới 2 . Kể cả ngành Môi trường khi đánh giá tiêu chí về "Số lượng cán bộ tham gia xây dựng hoặc thực hiện các dự án liên quan đến BĐKH” cũng ở mức dưới hạn chế. Giá trị này có nghĩa là đơn vị không có người hoặc nếu có là dưới 3 người có tham gia xây dựng hoặc thực hiện các dự án liên quan đến BĐKH; Phần lớn nhân lực cho nhiệm vụ này là kiêm nhiệm và đến từ các loại Phòng ban khác nhau (ở cấp Sở ngành) và Phòng Tài nguyên và môi trường ở cấp Quận/Huyện và không có ở cấp Phường/xã. Ngoài ra, phần lớn cán bộ kiêm nhiệm là không phù hợp chuyên môn (trừ nhóm ngành Môi trường).

5. Cơ chế tài chính liên quan đến $\mathrm{BĐKH} \mathrm{của}$ các đơn vị/lĩnh vực/ngành: tương tự tiêu chí " $\mathrm{Co}$. cấu tổ chức, nguồn nhân lực", điểm đánh giá của tiêu chí này cũng ở mức hạn chế $(1,93)$. Trong tiêu chí này, tiêu chí phụ về "Nguồn kinh phí cho các hoạt động liên quan đến BĐKH” và "Tính liên tục của nguồn tài chính cho công tác liên quan đến BĐKH” được đánh giá ở mức gần như rất hạn chế (chỉ có giá trị trung bình lần lượt là $1,34$ và 1,38$)$. Kinh phí nếu có sẽ được cấp theo dự án, không có nguồn chi thường xuyên nên không được cấp liên tục. Tiêu chí đánh giá về "Khả năng tìm được nguồn tài trợ trong và ngoài nước liên quan đến BĐKH” được đánh giá cao hơn hai tiêu chí được đề cập ở trên $(2,28)$. Lĩnh vực Nghiên cứu và Môi trường là hai lĩnh vực có cơ chế tài chính về ứng phó với BĐKH cao hơn so với các lĩnh vực còn lại do được thành phố cấp cho nguồn kinh phí để thực hiện các chương trình, dự án, nghiên cứu... Ngoài ra, hai lĩnh vực này là hai lĩnh vực có khả năng lớn nhất trong việc tìm được nguồn tài trợ trong và ngoài nước cho công tác liên quan đến BĐKH.

6. Cơ sở hạ tầng thích ứng với $\mathrm{BĐKH:} \mathrm{điểm}$ đánh giá của tiêu chí ở mức thấp $(2,11)$. Khả năng đáp ứng của cơ sở hạ tầng ở thời điểm hiện tại vốn đánh giá ở mức dưới trung bình $(2,31)$ càng thấp hơn trong điều kiện thời tiết bất thường $(2,17)$. Đánh giá về lộ trình xây dựng cơ sở hạ tầng theo quy hoạch, phần lớn cho rằng khó có thể theo kịp lộ trình đặt ra trong quy hoạch $(2,11)$. Đối với tiêu chí "Lồng ghép yếu tố BĐKH vào xây dựng quy hoạch", giá trị trung bình ở dưới mức hạn chế $(1,85)$, kể cả nhóm ngành quản lý cơ sở hạ tầng cũng đánh giá ở mức hạn chế $(1,99)$.

Qua kết quả tính trọng số các tiêu chí cho thấy, các tiêu chí được đánh giá có mức độ quan trọng cao phần lớn có giá trị trung bình ở mức hạn chế. Cụ thể tại bảng 7 .

\section{Kết luận}

Dựa vào kết quả tính trọng số để xác định mức độ quan trọng của tiêu chí có thể xác định một số các giải pháp trước mắt mà TP.HCM có thể áp dụng để khởi động quá trình nâng cao khả năng ứng phó với $\mathrm{BĐKH.} \mathrm{Theo} \mathrm{thứ} \mathrm{tự} \mathrm{ưu}$ tiên như sau: (1) Điều chỉnh quy hoạch có tính yếu tố BĐKH, chú trọng cơ sở hạ tầng đáp ứng được trong điều kiện $\mathrm{B} Đ K H$; (2) Xem xét bố trí 
nguồn kinh phí dành cho BĐKH (kể cả nguồn ngân sách và nguồn tài trợ), đặc biệt đảm bảo tính liên tục của kinh phí; (3) Nâng cao trình độ chuyên môn của cán bộ công chức viên chức về BĐKH; (4) Cơ cấu tổ chức, nguồn nhân lực về BĐKH; (5) Cải thiện tính khả thi của thể chế chính sách về $\mathrm{BĐKH;} \mathrm{(6)} \mathrm{Tăng} \mathrm{cường} \mathrm{chia} \mathrm{sẻ}$ dữ liệu giữa các bên liên quan.

Các tiêu chí được đánh giá dựa trên thang đo Likert từ 1 đến 5 , và mỗi giá trị được gán bằng nội dung cụ thể. Qua kết quả khảo sát cho thấy, các tiêu chí được đánh giá có mức độ quan trọng cao phần lớn có giá trị trung bình ở mức hạn chế. Kết quả đánh giá chung thể hiện khả năng thích ứng của mô hình quản lý đô thị tại TP.HCM ở mức thấp. Xét theo cấp quản lý, khả năng thích ứng của các đơn vị Sở/ngành cao hơn Quận/Huyện và Phường/Xã. Xét theo nhóm ngành, những ngành như môi trường, nghiên cứu và cơ sở hạ tầng có khả năng thích ứng với $\mathrm{BĐKH} \mathrm{cao} \mathrm{hơn} \mathrm{các} \mathrm{ngành} \mathrm{khác,} \mathrm{nhưng}$ vẫn dưới mức trung bình. Các ngành còn lại có sự tiếp cận hạn chế cả về thể chế chính sách, thông tin dữ liệu và sự tích hợp $\mathrm{BĐKH} \mathrm{vào}$ công tác quản lý.

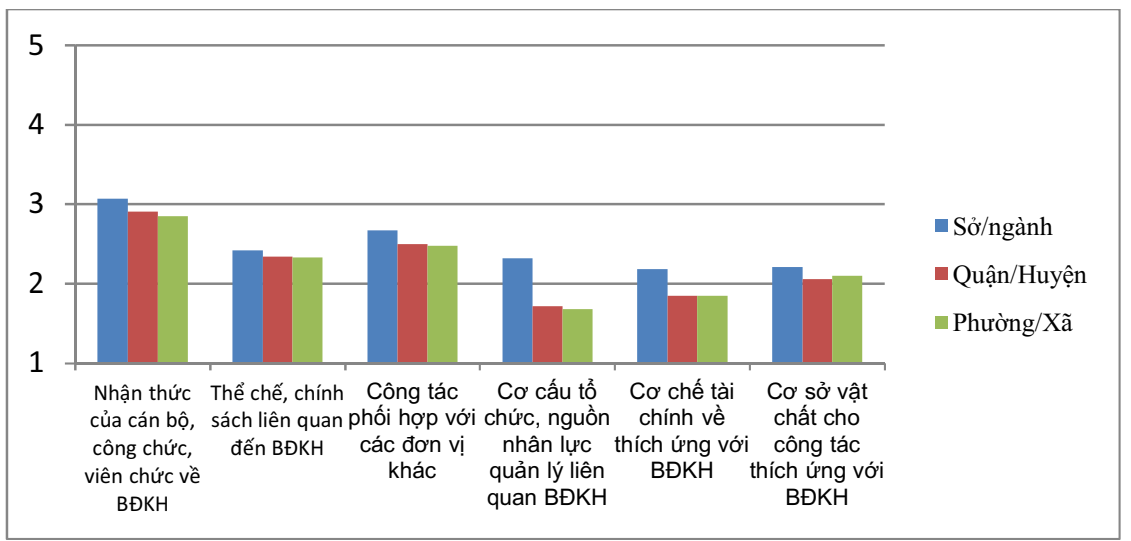

Hình 2. Giá trị của các tiêu chí chính (có trọng số) phân theo các cấp chính quyền

Bảng 6. Khả năng thích úng với BĐKH (phân theo lĩnh vục quản lý)

\begin{tabular}{|c|c|c|c|c|c|c|c|}
\hline Lĩnh vực & $\begin{array}{l}\text { Nhận } \\
\text { thức của } \\
\text { cán bộ, } \\
\text { công } \\
\text { chức, } \\
\text { viên chức } \\
\text { về } \\
\text { BĐKH }\end{array}$ & $\begin{array}{c}\text { Thể chế, } \\
\text { chính } \\
\text { sách } \\
\text { liên } \\
\text { quan } \\
\text { đến } \\
\text { BĐKH }\end{array}$ & $\begin{array}{l}\text { Công tác } \\
\text { phối hợp } \\
\text { với các } \\
\text { đơn vị } \\
\text { khác }\end{array}$ & $\begin{array}{l}\text { Cơ cấu tổ } \\
\text { chức, } \\
\text { nguồn } \\
\text { nhân lực } \\
\text { quản lý } \\
\text { liên quan } \\
\text { đến } \\
\text { BĐKH }\end{array}$ & $\begin{array}{c}\text { Cơ chế } \\
\text { tài } \\
\text { chính } \\
\text { về } \\
\text { thích } \\
\text { ứng với } \\
\text { BĐKH }\end{array}$ & $\begin{array}{l}\text { Cơ sở } \\
\text { vật chất } \\
\text { cho } \\
\text { công tác } \\
\text { thích } \\
\text { ứng với } \\
\text { BĐKH }\end{array}$ & $\begin{array}{c}\text { Điểm } \\
\text { TB }\end{array}$ \\
\hline Trọng số & 0,12 & 0,16 & 0,1 & 0,13 & 0,26 & 0,23 & \\
\hline Cơ sở hạ tầng & 2,99 & 2,41 & 2,57 & 1,99 & 1,91 & 2,23 & 2,27 \\
\hline $\begin{array}{l}\text { Dịch vụ xã } \\
\text { hội }\end{array}$ & 2,86 & 2,38 & 2,51 & 1,65 & 1,85 & 2,10 & 2,15 \\
\hline Môi trường & 3,07 & 2,36 & 2,62 & 2,38 & 2,05 & 2,14 & 2,34 \\
\hline $\begin{array}{l}\text { Nhà ở - xây } \\
\text { dựng - Quy } \\
\text { hoạch }\end{array}$ & 2,95 & 2,33 & 2,44 & 1,83 & 1,81 & 2,16 & 2,17 \\
\hline $\begin{array}{l}\text { Kinh tế - tài } \\
\text { chính }\end{array}$ & 2,92 & 2,31 & 2,51 & 1,65 & 1,88 & 2,19 & 2,18 \\
\hline $\begin{array}{l}\text { Tư pháp-Hộ } \\
\text { tịch-Pháp chế }\end{array}$ & 2,82 & 2,32 & 2,46 & 1,61 & 1,82 & 2,03 & 2,11 \\
\hline $\begin{array}{l}\text { Văn phòng- } \\
\text { Thống kê }\end{array}$ & 2,89 & 2,49 & 2,56 & 1,81 & 1,98 & 2,20 & 2,26 \\
\hline $\begin{array}{l}\text { Nghiên cứu, } \\
\text { báo chí,... }\end{array}$ & 2,85 & 2,21 & 2,57 & 1,81 & 2,24 & 2,24 & 2,29 \\
\hline Tổng & 2,92 & 2,35 & 2,53 & 1,85 & 1,93 & 2,11 & 2,21 \\
\hline
\end{tabular}


Bảng 7. Giá trị trung bình của các tiêu chí chính qua kết quả khảo sát

\begin{tabular}{|c|c|c|c|c|}
\hline STT & $\begin{array}{l}\text { Tiêu chí chính } \\
\text { (sắp xếp theo } \\
\text { múc dộ quan } \\
\text { trọng tùt cao } \\
\text { dến thấp theo } \\
\text { giá trị trọng số) }\end{array}$ & $\begin{array}{l}\text { Trọng số } \\
\text { (được sắp } \\
\text { xêp theo } \\
\text { thứ tư tù } \\
\text { cao xuống } \\
\text { thấp) }\end{array}$ & $\begin{array}{l}\text { Giá trị } \\
\text { trung bình } \\
\text { qua kết quả } \\
\text { khảo sát (tù̀ } \\
1 \text { đến 5) }\end{array}$ & Diễn giải \\
\hline 1 & $\begin{array}{ll}\text { Cơ chế } & \text { tài } \\
\text { chính } & \text { về } \\
\text { BĐKH } & \end{array}$ & 0,26 & 1,93 & $\begin{array}{l}\text { Được đánh giá có mức độ quan trọng } \\
\text { lớn nhất nhưng giá trị đánh giá thực } \\
\text { trạng hiện nay ở dưới mức thấp. Nguôn } \\
\text { kinh phí liên quan đến BĐKH không } \\
\text { có, hoặc nếu có được cấp theo dự án, } \\
\text { không liên tục. Khả năng tìm được } \\
\text { nguồn tài trợ trong và ngoài nước liên } \\
\text { quan đến BĐKH không cao. }\end{array}$ \\
\hline 2 & $\begin{array}{l}\text { Cơ sở hạ tầng } \\
\text { thích ứng với } \\
\mathrm{BĐKH}\end{array}$ & 0,23 & 2,11 & $\begin{array}{l}\text { Có mức độ quan trọng cao thứ } 2 \text { nhưng } \\
\text { giá trị đánh giá chỉ ở mức thấp. Khả } \\
\text { năng đáp ứng của cơ sở hạ tầng ở thời } \\
\text { điểm hiện tại không cao nên càng } \\
\text { không thể đáp ứng trong điều kiện thời } \\
\text { tiết bất thường. Lộ trình xây dựng cơ sở } \\
\text { hạ tầng theo quy hoạch không theo kịp } \\
\text { lộ trình và không xem xét lồng ghép } \\
\text { đầy đủ yếu tố BĐKH vào quy hoạch. }\end{array}$ \\
\hline 3 & $\begin{array}{l}\text { Thể chế, chính } \\
\text { sách liên quan } \\
\text { đến BĐKH }\end{array}$ & 0,16 & 2,36 & $\begin{array}{l}\text { Thể hiện thể chế, chính sách còn hạn } \\
\text { chế về tính bao quát, đầy đủ; tính khả } \\
\text { thi; tính hiệu quả; mức độ lồng ghép } \\
\text { BĐKH vào quản lý ngành và các mục } \\
\text { tiếu của thể chế, chính sách liên quan } \\
\text { đến BĐKH chưa rõ ràng cụ thể và có } \\
\text { thể đo lường được. }\end{array}$ \\
\hline 4 & $\begin{array}{l}\text { Cơ cấu tổ chức, } \\
\text { nguồn nhân lực } \\
\begin{array}{l}\text { quản lýn liên } \\
\text { quan } \\
\text { BĐKH dến }\end{array}\end{array}$ & 0,13 & 1,85 & $\begin{array}{l}\text { Có giá trị trung bình thấp nhất trong các } \\
\text { tiếu chí. Đơn vị không có người hoặc } \\
\text { nếu có là dưới } 3 \text { người có tham gia xây } \\
\text { dựng hoặc thực hiện các dự án liên } \\
\text { quan đến BĐKH; Phần lớn nhân lực } \\
\text { cho nhiệm vụ này là kiêm nhiệm và đến } \\
\text { từ các loại Phòng ban khác nhau (ở cấp } \\
\text { Sở ngành) và Phòng Tài nguyên và môi } \\
\text { trường ở cấp Quận/Huyện và không có } \\
\text { ở cấp Phường/xã. Ngoài ra, phần lớn } \\
\text { cán bộ kiêm nhiệm là không phù hợp } \\
\text { chuyên môn (trừ nhóm ngành Môi } \\
\text { trường) }\end{array}$ \\
\hline 5 & $\begin{array}{l}\text { Nhận thức của } \\
\text { cán bộ, công } \\
\text { chức, viên chức } \\
\text { về BĐKH }\end{array}$ & 0,12 & 2,92 & $\begin{array}{l}\text { Có giá trị đánh giá cao nhất so với các } \\
\text { tiêu chí khác. Thể hiện cán bộ, công } \\
\text { chức, viên chức tại TP.HCM có những } \\
\text { hiểu biết cơ bản về BĐKH, nhưng } \\
\text { nguồn thông tin dữ liệu về BĐKH chưa } \\
\text { được tiếp cận dễ dàng, đồng thời mức } \\
\text { độ cập nhật kiến thức liên quan đến } \\
\text { BĐKH cung không thường xuyên. }\end{array}$ \\
\hline 6 & $\begin{array}{l}\text { Công tác phối } \\
\text { hợp với các đơn } \\
\text { vị khác }\end{array}$ & 0,10 & 2,53 & $\begin{array}{l}\text { Cơ chế làm việc và phối hợp giữa các } \\
\text { bên liên quan chưa thực sự găn kêt, chủ } \\
\text { động, hầu như chỉ làm việc thông qua } \\
\text { công văn, văn bản. }\end{array}$ \\
\hline
\end{tabular}




\section{BÀI BÁO KHOA HỌC}

Lò̀i cảm ơn: Nhóm tác giả xin chân thành cảm ơn sự hỗ trợ kinh phí tù đề tài "Nghiên cứu mô hình quản lý đô thị tại Thành phố Hồ Chi Minh trong điều kiện biến đổi khí hậu” tù Sở Khoa học và công nghệ TP.HCM và xuất bản bài báo này.

\section{Tài Liệu Tham Khảo}

1. Võ Kim Cương (2006), Chính sách đô thị, Nhà xuất bản Xây dựng.

2. http:/occa.mard.gov.vn/Giai-phap-mo-hinh/Mo-hinh-thich-ung/catid/18/item/2829/khai-niemve-thich-ung-voi-bien-doi-khi-hau

3. Dự thảo Luật Quản lý phát triển đô thị (tháng 3 năm 2018).

4. McGraw-Hill (1982), Milan: Multiple (Tiêu chí ra quyết định), New York, p.17.

5. Ngân hàng Thế giới (2014), Tăng cuờng khả năng thích ưng của đô thị tại Cần Tho:

6. Tanner, T., Mitchell, T., Polack, E., Guenther, B. (2009), Khung đánh giá quản lý đô thị úng phó với $B Đ K H$.

7. Huỳnh Thị Lan Hương (2015), Nghiên cưu Phát triển Bộ chỉ số thích ứng với BĐKH phục vu công tác quản lý Nhà nuớc về $B Đ K H$. Viện Khoa học khí tượng thủy văn và Biến đổi khí hậu.

8. Lê Thị Kim Oanh (2016), Bước đầu nghiên cứu về di dân trong bối cảnh Biến đổi khí hậu và khả năng đáp úng của cơ sở hạ tầng ở TP.HCM. Sở Khoa học và Công nghệ TP.HCM.

9. Bộ Nông nghiệp và phát triển nông thôn (2015), Hỗ trợ rà soát, đánh giá các mô hình nông nghiệp thông minh thich ứng với biến đổi khi hậu ở Việt Nam, tù đó lựa chọn và đề xuất các mô hình phù hợp để nhân rộng.

10. WWF (2009), Mega-Stress for Mega-Cities: A Climate Vulnerability Ranking of Major Coastal Cities in Asia. World Wildlife Fund, pp. 40.

11. Điều chỉnh quy hoạch xây dựng vùng TP.HCM đến năm 2030 và tầm nhìn đến năm 2050 .

12. Nguyễn Tố Lăng (2018), Công tác quản lý phát triển đô thị bền vũng, một số bài học kinh nghiệm. Tham luận Hội thảo khoa học "Phát triển đô thị bền vững" tại TP.HCM.

13. Nguyễn Trọng Hòa (2015), Nghiên cứu chính quyền đô thị đáp ứng yêu cầu phát triển đô thị - Từ thực tiễn TP.HCM. Viện Nghiên cứu phát triển TP.HCM.

14. UBND TP.HCM (2018), Báo cáo so kết giai đoạn Chương trình nâng cao nguồn nhân lục giai đoạn 2016 - 2020, Văn bản báo cáo ngành.

15. Koop, S.H.A., Koetsier, L., Doornhof, A., Reinstra, O., Van Leeuwen, C.J., Brouwer, S., Dieperink, C., Driessen, P.P.J. (2017), Assessing the Governance Capacity of Cities to Address Challenges of Water, Waste, and Climate Change. Water Resources Management, 31, 3427-3443. DOI 10.1007/s11269-017-1677-7

16. Dalalah, D., AL-Oqla, F., Hayajneh, M. (2010), Application of the Analytic Hierarchy Process (AHP) in Multi-Criteria Analysis of the Selection of Cranes. Jordan Journal of Mechanical and Industrial Engineering, 4 (5), 567-578.

17. Yamane, T. (1967), Statistics, An Introductory Analysis, $2^{\text {nd }}$ Ed., New York: Harper and Row. 


\title{
EVALUATING THE URBAN ADAPTIVE CAPACITY TO CLIMATE CHANGE IN HO CHI MINH CITY
}

\author{
Tran Nhat Nguyen ${ }^{1}$, Nguyen Thi Minh Chau ${ }^{1}$, Le Thi Phung ${ }^{2}$, Nguyen Ky Phung ${ }^{3}$ \\ ${ }^{1} \mathrm{HCMC}$ Institute for Development Studies \\ ${ }^{2} \mathrm{HCMC}$ University of Natural Resources and Environment \\ ${ }^{3} \mathrm{HCMC}$ Deparment of Science and Technology
}

\begin{abstract}
Astract: Climate-resilient city $(C C)$ is an urban area that ensures the provision and operation of urban infrastructure systems for people in the event of natural disasters caused by climate change. Ho Chi Minh City (HCMC) is facing new challenges due to the impacts of climate change. To deal with the risk of climate change that threatens development goals, the city government should proactively enhance its resilience, especially in management. Climate change impacts to multiple fields. To evaluate the urban adaptive capacity to climate change in Ho Chi Minh City, we conducted the surveys for officials in 8 sectors (infrastructure, social services, environment, land - housing, economy, justice, research, offices - statistics) at HCMC government levels based on a set of criteria developed by the team. The results of the assessment help to identify existing issues from which there will be recommendations for adjustments in management in Ho Chi Minh City to improve the adaptive capacity to climate change of Ho Chi Minh City.
\end{abstract}

Keywords: Climate change, adaptive capacity, urban governance, Hochiminh City. 